Journal for ImmunoTherapy of Cancer

\title{
Nanoencapsulated rituximab mediates superior cellular immunity against metastatic B-cell lymphoma in a complement competent humanized mouse model
}

\author{
Jing Wen, ${ }^{1,2}$ Lan Wang, ${ }^{1,2}$ Jie Ren, ${ }^{3}$ Emiko Kranz, ${ }^{1,2}$ Shilin Chen, ${ }^{3}$ Di Wu, ${ }^{3}$ \\ Toshio Kanazawa, ${ }^{1,2}$ Irvin Chen, ${ }^{1,2}$ Yunfeng Lu, ${ }^{3}$ Masakazu Kamata (i) ${ }^{4}$
}

To cite: Wen J, Wang L, Ren J, et al. Nanoencapsulated rituximab mediates superior cellular immunity against metastatic B-cell lymphoma in a complement competent humanized mouse model. Journal for ImmunoTherapy of Cancer 2021;9:e001524. doi:10.1136/jitc-2020-001524

- Additional material is published online only. To view, please visit the journal online (http://dx.doi.org/10.1136/jitc2020-001524).

JW and LW contributed equally. Accepted 17 December 2020

Check for updates

(C) Author(s) (or their employer(s)) 2021. Re-use permitted under CC BY-NC. No commercial re-use. See rights and permissions. Published by BMJ.

For numbered affiliations see end of article.

Correspondence to Dr Masakazu Kamata; masa3k@uab.edu

\section{ABSTRACT}

Background Despite the numerous applications of monoclonal antibodies (mAbs) in cancer therapeutics, animal models available to test the therapeutic efficacy of new mAbs are limited. NOD.Cg-Prkd $c^{\text {sid }} \| 2 \mathrm{rg}^{\text {tmiWjl }^{\mathrm{m}}} / \mathrm{SzJ}$ (NSG) mice are one of the most highly immunodeficient strains and are universally used as a model for testing cancer-targeting mAbs. However, this strain lacks several factors necessary to fully support antibody-mediated effector functions-including antibody-dependent cellular cytotoxicity, antibody-dependent cellular phagocytosis, and complement-dependent cytotoxicity (CDC) — due to the absence of immune cells as well as a mutation in the $H c$ gene, which is needed for a functional complement system.

Methods We have developed a humanized mouse model using a novel NSG strain, NOD.Cg ${ }^{-H c 1}$ Prkdc ${ }^{\text {sid }}$ II2rgtm1Wj/SzJ (NSG ${ }^{-\mathrm{Hc} 1}$ ), which contains the corrected mutation in the $\mathrm{Hc}$ gene to support CDC in addition to other mechanisms endowed by humanization. With this model, we reevaluated the anticancer efficacies of nanoencapsulated rituximab after xenograft of the human Burkitt lymphoma cell line 2F7-BR44.

Results As expected, xenografted humanized NSG ${ }^{-H c 1}$ mice supported superior lymphoma clearance of native rituximab compared with the parental NSG strain. Nanoencapsulated rituximab with CXCL13 conjugation as a targeting ligand for lymphomas further enhanced antilymphoma activity in $\mathrm{NSG}^{-\mathrm{Hc} 1}$ mice and, more importantly, mediated antilymphoma cellular responses. Conclusions These results indicate that $\mathrm{NSG}^{-\mathrm{Hc} 1}$ mice can serve as a feasible model for both studying antitumor treatment using cancer targeting as well as understanding induction mechanisms of antitumor cellular immune response.

\section{INTRODUCTION}

Therapeutic monoclonal antibodies (mAbs) such as anti-CD20 rituximab (RTX) for non-Hodgkin's lymphoma (NHL) and trastuzumab/Herceptin (anti-Her2) for breast cancer have revolutionized cancer treatments. ${ }^{12}$ However, many previously developed mouse models used in cancer research have limited utility in evaluating immune system-based cancer therapeutics due to their deficient or non-human immune system. ${ }^{3}$ To create a superior system for successful engraftment of human cells, advanced immunodeficient NOD.Cg-Prkd $c^{s c i d} \quad I l 2 r g^{t m l W j l} / \mathrm{SzJ}$ (NSG) mice lacking the common cytokinereceptor $\gamma$-chain (IL-2R $\gamma$ ) were developed and have been widely used. ${ }^{4}$ NSG mice have a highly impaired immune system including $\mathrm{B}$ cell, T cell, and natural killer (NK) cell development, reduced dendritic cell function and macrophage activity, and innate immune deficiencies. ${ }^{5}$ Though NSG mice are considered effective for tumor xenografts, the therapeutic effect of $\mathrm{mAbs}$ is primarily mediated by antibody-induced apoptosis. Therefore, the NSG strain cannot be used for complete evaluation of mAb activity due to a lack of support for other mechanisms of antibody-mediated cytotoxicity such as complement-dependent cytotoxicity (CDC), antibody-dependent cellular cytotoxicity (ADCC), or antibodydependent cellular phagocytosis (ADCP). ${ }^{6}$

Immunodeficient mice reconstituted with a human immune system, termed "humanized mice," have been developed and used in various research fields. ${ }^{7}$ In particular, the bone marrow-liver-thymus (BLT) humanized mouse model provides robust and functional $\mathrm{T}$ cells. ${ }^{8}$ We have adapted BLT mice using the NSG strain in cancer immunotherapy research. ${ }^{9}$ The therapeutic efficacy of mAbs proved more efficacious in the adapted mice than that in NSG mice, probably due to the support of ADCC and ADCP mediated by reconstituted human NK cells and macrophages. ${ }^{9}$ However, NSG mice still lack 
the hemolytic complement $(H c)$ gene due to a 2 bp deletion in the coding region. ${ }^{10}$ The $\mathrm{Hc}$ gene encodes the $\mathrm{C} 5$ complement components needed to generate a functional membrane attack complex (MAC) involved in shaping the inflammatory tumor microenvironment, mediating CDC, and regulating angiogenesis and hypoxia. ${ }^{11}$ Direct infusion of human complement was performed to establish a functional complement system in immunodeficient murine models, but its support of CDC was affected by the source, volume, and injection frequency of human serum. ${ }^{12}$

In a previous study, we created a murine xenograft model of NHL by transplanting a human 2F7 Burkitt NHL cell line established from a patient with AIDS-lymphoma into NSG-BLT humanized mice. One of the clones, 2F7-BR44, is highly metastatic; cells initially migrate into the lungs after tail vein injection, followed by systemic distribution, including to the central nervous system (CNS), within 1 week. ${ }^{9}$ Using this model, we showed that (1) nanoencapsulation of RTX within a 2-methacryloyloxyethyl phosphorylcholine (MPC) polymer-based nanocapsule (n-RTX) enables RTX to traverse the blood brain barrier (BBB), resulting in an approximately 10-fold increase in concentration of released RTX in cerebrospinal fluid, (2) conjugation of CXCL13 on the surface of n-RTX as a targeting ligand for B-cell lymphomas (n-RTX ${ }^{\text {CXCL13 }}$ ) mediates efficient lymphoma targeting in the brain, and (3) n-RTX ${ }^{\text {CXCL13 }}$ enables elimination of all tumors to undetectable levels. To evaluate the efficacy of anticancer mAbs in a more clinically-relevant small animal model, we herein report a novel humanized BLT mouse model with a newly developed NSG derivative strain, NOD.Cg${ }^{\mathrm{Hcl}} \operatorname{Prkdc}^{\text {scid }}$ Il2rgtm1Wjl/SzJ ( $\mathrm{NSG}^{-\mathrm{Hcl}}$ ) mouse that has corrected $H c$ gene. ${ }^{13}$ Since $\mathrm{NSG}^{-\mathrm{Hcl}}$ mice have been shown to support the CDC mechanism of native RTX in a xenograft model,${ }^{14}$ the BLT model $\left(\mathrm{NSG}^{-\mathrm{Hcl}}\right.$-BLT) is expected to support all four known cytotoxic effector mechanisms mediated by RTX (apoptosis, CDC, ADCC, and ADCP) under a human immune environment in mice. Using $\mathrm{NSG}^{-\mathrm{Hc} 1}$-BLT mice, we reevaluated antilymphoma activity of n-RTX ${ }^{\mathrm{CXCL} 13}$ in the 2F7-BR44 xenograft humanized mouse model compared with that in NSG-BLT mice. The results indicate that $\mathrm{NSG}^{-\mathrm{Hcl}}$-BLT supports superior antilymphoma efficacy mediated by n-RTX ${ }^{\text {CXCL13 }}$, but surprisingly, this new model treated with n-RTX CXCL13 supported the establishment of an antilymphoma cellular response-likely antitumor vaccine effects mediated via antigen-antibody immune complexes. ${ }^{15}{ }^{16}$ We expect that $\mathrm{NSG}^{-\mathrm{Hcl}}$-BLT will open new avenues for developing antitumor therapies using cancer-targeting mAbs.

\section{MATERIALS AND METHODS}

\section{Reagents and mice}

All chemicals and proteins were purchased from SigmaAldrich (St. Louis, Missouri, USA) unless otherwise noted. All cell culture reagents were purchased from ThermoFisher Scientific (Waltham, Massachusetts, USA) unless otherwise noted. Hydrolysable crosslinker poly(DLlactide)-b-poly(ethylene glycol)-b-poly(DL-lactide)diacrylate triblock (PLA-PEG-PLA) was purchased from PolySciTech Akina (West Lafeyette, Indiana, USA). Capture antibody for ELISA against RTX was purchased from Bio-Rad Laboratories (MCA2260, Hercules, California, USA). HRP-conjugated goat antihuman IgG Fc for ELISA assay was purchased from ThermoFisher Scientific. Antihuman CD45, antihuman CD3, antihuman CD56, antihuman $\mathrm{CD} 11 \mathrm{~b}$, antihuman $\mathrm{CD} 14$, antihuman CD4, and antihuman CD8 were purchased from BioLegend (San Diego, California,USA). RTX (RITUXANTM: Genentech, San Francisco, California,USA) and HER (Herceptin: Genentech) were obtained at the UCLA hospital pharmacy. All NOD.Cg-Prkde $c^{\text {scid }} \mathrm{Il} \mathrm{rg}^{\text {tmlWjl}} / \mathrm{SzJ}$ (NSG) and NOD.Cg ${ }^{-\mathrm{Hcl}}$ Prkdc $^{\text {scid }}$ Il2rgtm1Wjl/SzJ (NSG ${ }^{\mathrm{Hc1}}$ ) mice were purchased from The Jackson Laboratory and housed in specific pathogen-free vivarium.

\section{Synthesis of RTX nanocapsules (n-RTX)}

The n-RTX were synthesized with optimized modification for antibodies based on our previous reports. ${ }^{9}{ }^{17}$ Briefly, RTXs were encapsulated via in situ polymerization at room temperature using MPC as the monomer, PLA-PEG-PLA and glycerol dimethacrylate (GDMA) as the crosslinker, and ammonium persulfate and $\mathrm{N}, \mathrm{N}, \mathrm{N}^{\prime}, \mathrm{N}^{\prime}$-tetramethylethylenediamine (TEMED) as the initiator. The n-RTX with mixed crosslinkers of GDMA and PLA-PEG-PLA at a 1:1 molar ratio (n-RTX) were synthesized with optimized modification for antibodies based on our previous reports. The n-RTX were synthesized using a volume of $5 \mathrm{mg}$ RTX at $1.5 \mathrm{mg} / \mathrm{mL}$, a specific amount of MPC $(40 \% \mathrm{~m} / \mathrm{v}$ in PBS), PLA-PEG-PLA $(10 \% \mathrm{~m} / \mathrm{v}$ in PBS) and GDMA $(10 \% \mathrm{~m} / \mathrm{v}$ in Dimethyl Sulfoxide (DMSO) $)$ in a molar ratio of RTX:MPC:PLA-PEG-PLA:GDMA=1:12 000:500:500. Free-radical polymerization from the protein surface was then initiated by adding ammonium persulfate $(10 \% \mathrm{~m} / \mathrm{v}$ in Phosphate buffered saline (PBS), molar ratio to $\mathrm{RTX}=2000: 1$ ) and TEMED (molar ratio to RTX $=4000: 1)$ to the reaction vial and kept in an ice bath for 2 hours. Finally, dialysis was used to remove extra free monomers and initiators. The free RTX was removed using hydrophobic interaction chromatography (Phenyl Sepharose CL-4Bh) as described previously.

\section{Synthesis of Saporin nanocapsules ( $\mathrm{n}$-Saporin ${ }^{\text {anti-CD7}}$ )}

The n-Saporin without anti-CD7 conjugation were synthesized using a volume of $100 \mu \mathrm{g}$ Saporin at $1 \mu \mathrm{g} / \mu \mathrm{L}$, a specific amount of acrylamide (AAm, $10 \% \mathrm{~m} / \mathrm{v}$ in PBS), $\mathrm{N}$-(3-aminopropyl)methacrylamide (APm, $10 \% \mathrm{~m} / \mathrm{v}$ in PBS), citraconic anhydride N-(3-aminopropyl) methacrylamide (cit-APm, $10 \% \mathrm{~m} / \mathrm{v}$ in PBS) and GDMA $(10 \% \mathrm{~m} / \mathrm{v}$ in DMSO) in a molar ratio of Saporin:AAm:APm:citAPm:GDMA=1:6000:100:100:500. Radical polymerization from the surface of the protein was then initiated by adding ammonium persulfate $(10 \% \mathrm{~m} / \mathrm{v}$ in PBS, molar ratio to Saporin $=2000: 1$ ) and TEMED (molar ratio to Saporin=4000:1) to the reaction vial and kept in an 
ice bath for 2 hours. Finally, dialysis was used to remove extra free monomers and initiators. The free Saporin was removed using hydrophobic interaction chromatography (Butyl-S Sepharose 6 Fast Flow columns; GE Healthcare). Anti-CD7 antibodies were conjugated onto nanocapsules through copper-free click chemistry to form n-Saporin ${ }^{\text {an- }}$ ti-CD7. Dibenzocyclooctyne-PEG4-N-hydroxysuccinimidyl ester (DBCO-PEG4-NHS) in DMSO $(11 \mathrm{mg} / \mathrm{mL})$ was added into the nanocapsule solution at a 10:1 molar ratio. NHS-PEG4-Azide in DMSO $(39 \mathrm{mg} / \mathrm{mL})$ was added into the anti-CD7 solution at a 10:1 molar ratio. Both reactions were processed in an ice bath for 1 hour. Free reagents were removed by size-exclusion spin columns. The conjugation between DBCO-modified n-Saporin and azidemodified anti-CD7 was reacted at $4^{\circ} \mathrm{C}$ for 17 hours at a $1: 1$ molar ratio to synthesize $n-S a p o r i{ }^{\text {anti-CD7 }}$.

\section{Cell culture}

2F7-BR44 cells were transduced with a lentiviral vector encoding mStrawberry and firefly luciferase (Fluc) together with the bleomycin-resistant gene under elongation factor- $1 \alpha$ promoter and maintained in Iscove's Modified Dulbecco's supplemented with $15 \%$ fetal bovine serum, $1 \%$ GlutaMax, $1 \%$ Antibiotic-Antimycotic, and $200 \mu \mathrm{g} /$ $\mathrm{mL}$ of Zeocin.

\section{Cytotoxicity assay}

Antilymphoma activity of RTX on 2F7-BR44 cells was assessed by absolute cell number counting using MACSQuant Analyzer 10 (Miltenyi Biotech, Bergisch Gladbach, Germany). For CDC testing, 2F7-BR44 cells were cultured in 24-well plates $\left(1 \times 10^{6} / \mathrm{mL}\right)$ for 24 hours in the presence of RTX $(20 \mu \mathrm{g} / \mathrm{mL})$ and $20 \%$ murine serum from either NSG or $\mathrm{NSG}^{-\mathrm{Hcl}}$ mice. For the PBS control group, 2F7-BR44 were cultured in 24-well plates $\left(1 \times 10^{6}\right.$ / $\mathrm{mL})$ for 24 hours in the presence of RTX $(20 \mu \mathrm{g} / \mathrm{mL})$ and $20 \%$ of PBS. The same volumes of cell culture were taken to obtain absolute cell numbers on MACSQuant Analyzer 10. Cell death percentages were calculated as cell death $(\%)=100 \times(1-($ cell number after RTX treatment/control without RTX)).

\section{Cell surface marker staining}

2F7-BR44 cells were washed with 2\% fetal bovine serum/ PBS. Seven antibodies of cell surface markers-CD45, CD3, CD56, CD11b, CD14, CD4, and CD8 -were added and stained at $4^{\circ} \mathrm{C}$ for $30 \mathrm{~min}$. Expression levels were assessed by BD LSRFortessa (BD Biosciences, San Jose, California, USA) after fixation with $2 \%$ formaldehyde in PBS.

\section{Antibody half-life studies}

In vivo half-life of native RTX and n-RTX was determined by monitoring the free RTX concentration in plasma from NSG and $\mathrm{NSG}^{-\mathrm{Hcl}}$ mice. Briefly, NSG and $\mathrm{NSG}^{-\mathrm{Hcl}}$ mice were randomly divided into two groups and retroorbitally injected at a dosage of $20 \mathrm{mg} / \mathrm{kg} /$ mouse, a dose which has been reported as effective in an NHL xenograft murine model. ${ }^{9}$ The concentration of free RTX in plasma samples was detected by ELISA using the VersaMaxTM Tunable microplate reader (Molecular Devices, San Jose, California, USA).

\section{MAb detection by ELISA}

The concentration of RTX in plasma was measured by ELISA using anti-RTX antibody and peroxidaseconjugated antihuman Fc antibody as described previously. ${ }^{918}$

\section{Complement inactivation}

To inactivate complement in $\mathrm{NSG}^{-\mathrm{Hc} 1}$ serum for in vitro test, the serum was incubated in a water bath at $56^{\circ} \mathrm{C}$ for $30 \mathrm{~min}$. The complement activity of $\mathrm{NSG}^{-\mathrm{Hcl}}$ serum was depleted by cobra venom factor (CVF) treatment in vivo. $\mathrm{NSG}^{-\mathrm{Hcl}}$ mice $(\mathrm{n}=4)$ were treated with $1 \mathrm{mg} / \mathrm{kg}$ of CVF at Day $0,6,13$, and 21 via intraperitoneal injection. The complement C3 depletion by CVF was confirmed by commercial mouse C3 specific ELISA (Abcam, Cambridge, UK). The 50\% hemolytic complement activity (CH50) in serum was tested with by hemolytic assay. In brief, serially diluted serum samples were incubated with red blood cells and hemolysin at $37^{\circ} \mathrm{C}$ for $30 \mathrm{~min}$. The lysis of red blood cells was detected by reading the absorbance of the samples at $540 \mathrm{~nm}$. The \%lysis was calculated using the following formula optical density $(\mathrm{OD}): \%$ lysis $=(\mathrm{OD}-$ ${ }_{540}$ test $-\mathrm{OD}_{540}$ blank $) /\left(\mathrm{OD}_{540}\right.$ total lysis $-\mathrm{OD}_{540}$ blank $) \times 100 \%$ and plotted with the serum dilutions. The serum dilution required for $50 \%$ hemolysis was read out as the $\mathrm{CH} 50$ at each time point. The $\mathrm{CH} 50$ was normalized to day 0 (Setpoint) and plotted as normalized CH50 (Test time point/Setpoint). The serum from NSG mice was included as a negative control for the $\mathrm{CH} 50$ assay.

\section{In vivo imaging to monitor lymphoma progression}

2F7-BR44 cells were gene marked with a lentiviral vector expressing firefly luciferase, then luciferase-expressing cells were selected through a week of Zeocin treatment $(200 \mu \mathrm{g} / \mathrm{mL})$. The selected 2F7-BR44 cells $\left(2 \times 10^{6} /\right.$ animal) were injected into 6 week-old male $\mathrm{NSG}^{-\mathrm{Hcl}}$ mice via the tail vein to obtain lymphoma xenograft mice. One or 2 weeks after 2F7-BR44 cell injection, mice were treated with a single course of native RTX or n-RTX ${ }^{\text {CXCL13 }}$ via retro-orbital vein injection $(4 \mathrm{mg} \mathrm{kg} /$ day for five sequential days). Lymphoma formation was monitored by in vivo bioimaging using the IVIS Lumina II (PerkinElmer, Waltham, Massachusetts, USA). In vivo bioluminescence imaging was performed following subcutaneous injection of $4.5 \mathrm{mg}$ D-luciferin (Pierce, Woodland Hills, California, USA). Mice were imaged at the signal plateau (10 min post-D-luciferin injection) under isoflurane anesthesia.

Humanized mice were prepared as previously described with modifications. ${ }^{9}$ Human fetal liver and thymus tissues from the identical donors were obtained from Advanced Biosciences Resources or Novogenix without identifying information and did not require Institutional Review Boards (IRB) approval for its use. Six-week-old male NSG or $\mathrm{NSG}^{-\mathrm{Hc1}}$ mice were administered Busulfan $(35 \mathrm{mg} / \mathrm{kg})$ 
intraperitoneally. 24 hours later, the mice were implanted with a portion of human fetal thymus combined with $0.5 \times 10^{6}$ fetal liver-derived CD34 ${ }^{+}$cells obtained from the same donor after solidification in the Matrigel under the kidney capsule and also injected with $0.5 \times 10^{6} \mathrm{CD} 34+$ cells via retro-orbital vein. After the human blood cell reconstitution in peripheral blood, 2F7-BR44 cells $\left(2 \times 10^{6} /\right.$ animal) were injected into humanized BLT mice via tail vein to establish xenograft humanized BLT mice. One or 2 weeks after 2F7-BR44 cell injection, mice were treated with a single course of native RTX or $\mathrm{n}-\mathrm{RTX}^{\mathrm{CXCL13}}$ via retro-orbital vein injection $(4 \mathrm{mg} \mathrm{kg} /$ day for five sequential days). Lymphoma formation was monitored by in vivo bioimaging using the IVIS Lumina II.

Lymphoma burden in both xenograft and xenograft humanized BLT mice was quantified as the total photon flux per second within a region of interest (ROI) whole body of the mouse; ROIs were identically sized for all measurements.

\section{Statistical analyses}

Results are expressed as mean \pm SDs. Errors depict SD. Statistical significance is presented with a $\mathrm{p}$ value calculated by the GraphPad Prism (La Jolla, California, USA). The significance of survival curve was compared with a log-rank test. All other significance comparisons between groups were calculated by either Wilcoxon matchedpaired signed rank test or one-tailed unpaired $t$-test with Welch's correction, which clarified for each figure legend. $\mathrm{P}>0.05$ was not considered statistically significant and noted not significant.

\section{RESULTS}

\section{Establishment of lymphoma development in immunodeficient} $\mathrm{NSG}^{-\mathrm{Hc1}}$ mice

We have established a highly metastatic 2F7-BR44 lymphoma cell line obtained from a CNS lymphoma. ${ }^{9}$ This cell line was subcloned from the human 2F7 Burkitt NHL cell line, which was retrieved from an patient with AIDS-lymphoma ${ }^{19}$ and selected for its high rate of metastasis $(100 \%)$ to the CNS. ${ }^{9}$ The 2 F7-BR44 cells were modified to express firefly luciferase (Fluc), which allows us to track both cancer spread and therapeutic efficacy through in vivo bioluminescence imaging. These cells also express mStrawberry, which enables their detection by flow cytometry. Although this cell line has already been tested for xenograft mouse generation using NSG or humanized NSG mice in our previous work, ${ }^{9}$ the impact of complement on xenografts is unknown. We first generated a 2F7-BR44 cell xenograft using $\mathrm{NSG}^{-\mathrm{Hc1}}$ mice and compared lymphomagenesis to that of NSG mice. There was no distinct difference in the timing of lymphoma formation and tissue distribution between two strains of NSG (figure 1: $\mathrm{NSG}^{-\mathrm{Hc1}}$ vs online supplemental figure S1:
A

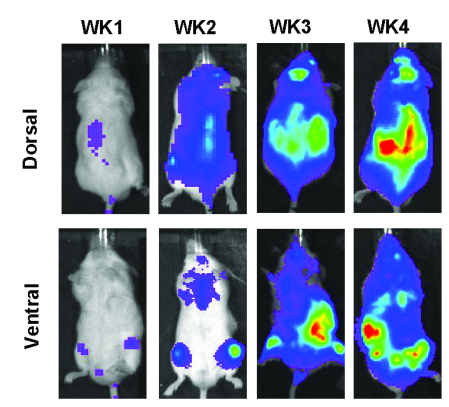

B

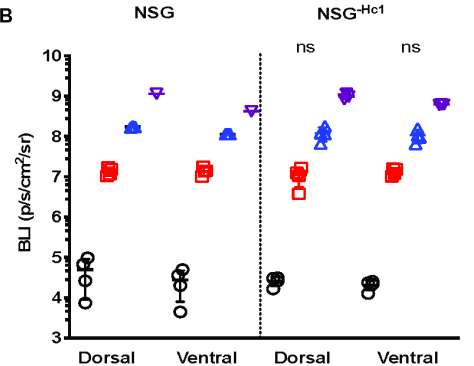

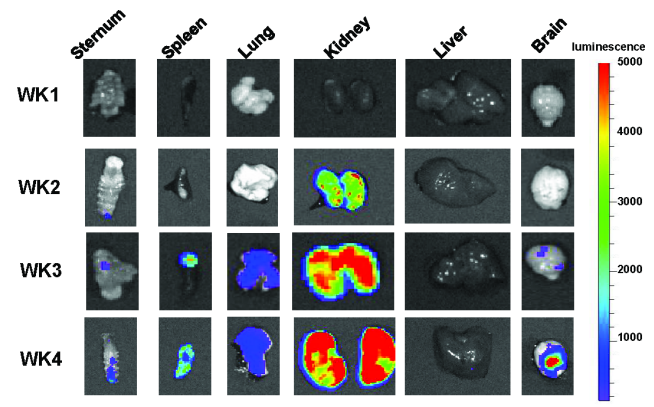

C
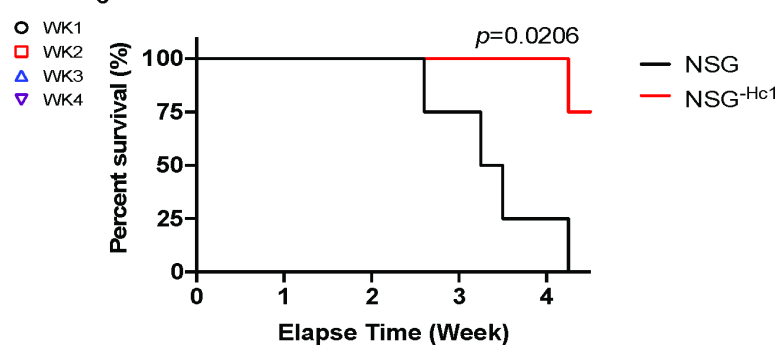

Figure 1 Establishment of 2F7-BR44 lymphoma xenograft mouse models using the $\mathrm{NSG}^{-\mathrm{Hc}^{1}}$ strain. (A) A series of in vivo bioluminescent images of a representative xenograft $\mathrm{NSG}^{-\mathrm{Hc} 1}$ mouse engrafted with luciferase-labeled 2F7-BR44 cells. 2F7BR44 cells were transplanted to $\mathrm{NSG}^{-\mathrm{Hc} 1}$ mice $(n=4)$ via tail vein $\left(2 \times 10^{6} /\right.$ animal). Representative bioluminescent images from the same animal were taken on IVIS Lumina II In vivo imaging system at weeks 1, 2, 3, and 4 post xenograft. Tissue images were obtained from the same mouse after the whole-body imaging. Sensitivity settings were adjusted at each time point to maintain 500-5000 counts per pixel and assigned the same color scale for all time points. (B) Bioluminescence intensity (BLI) values in the whole body were compared between NSG and $\mathrm{NSG}^{-\mathrm{Hc}^{1}}$ xenograft mice. Data are shown means $\pm \mathrm{SDs}$. The statistical significance was calculated to NSG group by one-tailed unpaired t-test with Welch's correction. (C) Kaplan-Meier survival curves of the NSG and $\mathrm{NSG}^{-\mathrm{Hc} 1}$ xenograft mice from the same experiment were plotted relative to the number of weeks after 2F7-BR44 cell xenograft. Statistical significance was calculated with $p$ value by log-rank test. ns; not significant. 
NSG). Side-by-side comparison of total bioluminescence intensities further supported the similarity in lymphomagenesis between the two xenograft models (figure 1B) even though a higher survival rate was observed in NSG ${ }_{\mathrm{Hc} 1}$ mice (figure 1C). These results indicate that the fully functional complement system cannot sufficiently mediate antilymphoma activity.

NSG $^{-H c 1}$ mice support increased antilymphoma activity of RTX A functional complement system is beneficial to the mediation of additional antilymphoma activity of RTX. ${ }^{14}$ To confirm this point, we first tested RTX-mediated cytotoxicity against 2F7-BR44 cells in the presence of serum obtained from both NSG and $\mathrm{NSG}^{-\mathrm{Hcl}}$ mice, as well as heat-inactivated $\mathrm{NSG}^{-\mathrm{Hcl}}$ serum in vitro (online supplemental figure S2). Compared with the presence of serum from NSG, approximately three-fold higher levels of cell death induced by RTX were confirmed with $\mathrm{NSG}^{-\mathrm{Hcl}}$ serum; however, the improvement lost when the complement in $\mathrm{NSG}^{-\mathrm{Hcl}}$ serum was inactive by heat inactivation. This indicates that the presence of functional complement plays a valuable role in enhancing antilymphoma effector activity of RTX. We next verified the impact of the presence of functional complement system on RTX efficacy by comparing lymphoma growth among xenograft $\mathrm{NSG}, \mathrm{NSG}^{-\mathrm{Hcl}}$, and $\mathrm{NSG}^{-\mathrm{Hcl}}$ diminished complement activity by the administration of $\mathrm{CVF}-\mathrm{a}$ glycoprotein cleaves complement C3 to C3a and C3b by its enzyme form complexed with factor $\mathrm{B}$ and factor $\mathrm{D},{ }^{20}$ resulting in impairment of functional MAC (figure 2). To monitor the effect of CVF treatment, complement activities in the treated animals were determined by both mouse complement C3 ELISA and the 50\% hemolytic complement
(CH50) activity in serum through hemolytic assay. ${ }^{21}$ As shown in online supplemental figure $\mathrm{S} 3$, the complement activity significantly decreased in $\mathrm{NSG}^{-\mathrm{Hcl}}$ mice with each CVF treatment, which was still higher than that in NSG mice.

Antilymphoma activity of RTX was monitored weekly by bioluminescence after the administration of native RTX $(100 \mu \mathrm{g} /$ day/animal) five times at 1 week post xenograft. Native RTX treatment delayed lymphoma formation in both xenograft mouse models relative to no treatment (compare figure 2A with figure 1A and online supplemental figure S1). Although lymphomagenesis tended to slow progressively in $\mathrm{NSG}^{-\mathrm{Hcl}}$ mice than that in NSG, the difference became negligible between NSG mice and $\mathrm{NSG}^{-\mathrm{Hcl}}$ mice with $\mathrm{CVF}$ treatment (compare week 4 results in figure 2B). The difference was not statistically significant due to high variations, but it suggested that a functional complement system in the $\mathrm{NSG}^{-\mathrm{Hc} 1}$ strain could support enhanced antilymphoma activity of native RTX as reported. ${ }^{14}$

\section{Nanoencapsulated RTX effectively controls systemic and CNS lymphoma formation in $\mathrm{NSG}^{-\mathrm{Hc} 1}$ xenografted mice}

We previously reported that the encapsulation of RTX within a zwitterionic MPC polymer layered together with surface conjugation of CXCL13-the CXCR5 ligandfor B-cell lymphoma targeting (denoted as n-RTX ${ }^{\text {CXCL13 }}$ ) leads to sustained release and increases CNS levels of free RTX by approximately 10 -fold via enhanced penetration of the BBB with respect to the administration of native RTX in NSG mice. The treatment of xenograft NSG mice with n-RTX ${ }^{\text {CXCL13 }}$ exhibited significantly superior control of lymphoma progression compared with that of native

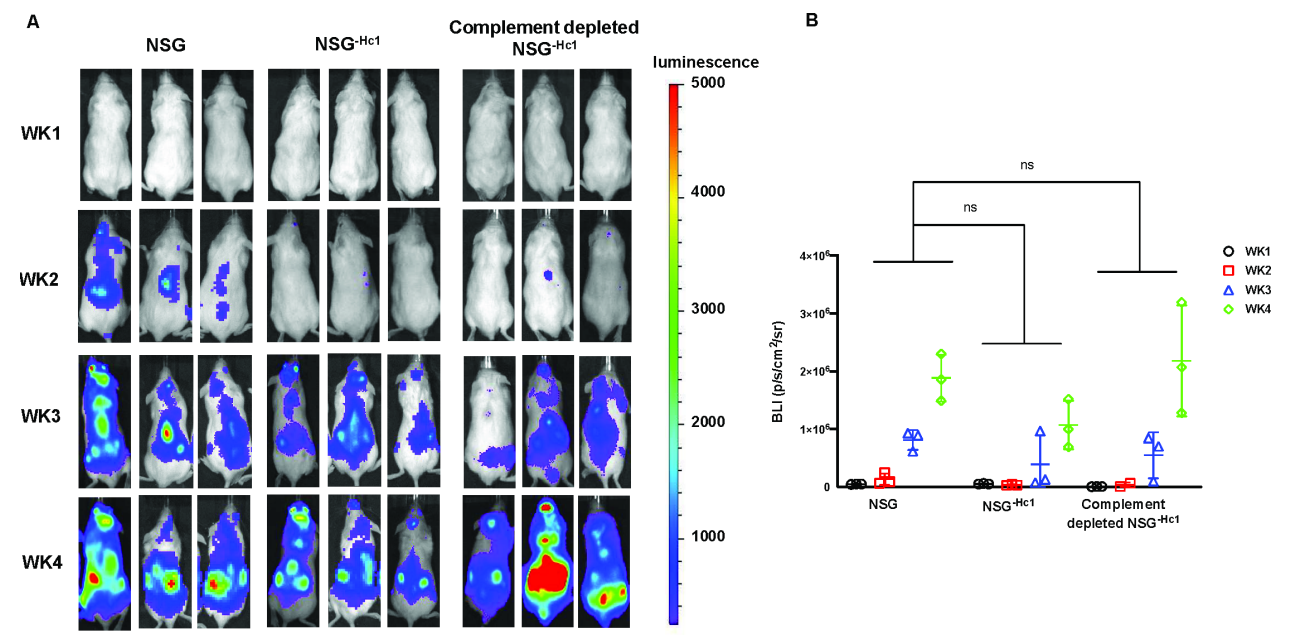

Figure 2 Antilymphoma efficacy of RTX in NSG and NSG ${ }^{-H c 1}$ xenografted mice. 2F7-BR44 cells were injected into NSG, $\mathrm{NSG}^{-\mathrm{Hc} 1}$ and complement depleted mice via the tail vein $\left(2 \times 10^{6} / \mathrm{animal}\right)(\mathrm{n}=3)$. All xenograft mice were treated with $\mathrm{RTX}$ at week 1 after 2F7-BR44 cell injection. Native RTX was injected via the retro-orbital vein ( $4 \mathrm{mg} / \mathrm{kg} /$ day for 5 sequential days). (A) Lymphoma progression and metastasis were monitored weekly by bioluminescence imaging using an IVIS Lumina II In Vivo Imaging system. Sensitivity settings were adjusted at each time point to maintain 250-5000 counts per pixel and assigned the same color scale for all time points. (B) Bioluminescence intensity (BLI) values in the whole body with native RTX treatment were compared between xenograft NSG and NSG ${ }^{-\mathrm{Hc} 1}$ mice, as well as between xenograft NSG and complement depleted $\mathrm{NSG}^{-\mathrm{Hc}^{1}}$ mice. Data are shown means \pm SDs. Statistical significance was calculated with means at all four time points using a $p$ value. $P$ values were calculated by Wilcoxon matched-paired signed rank test. ns; not significant. 

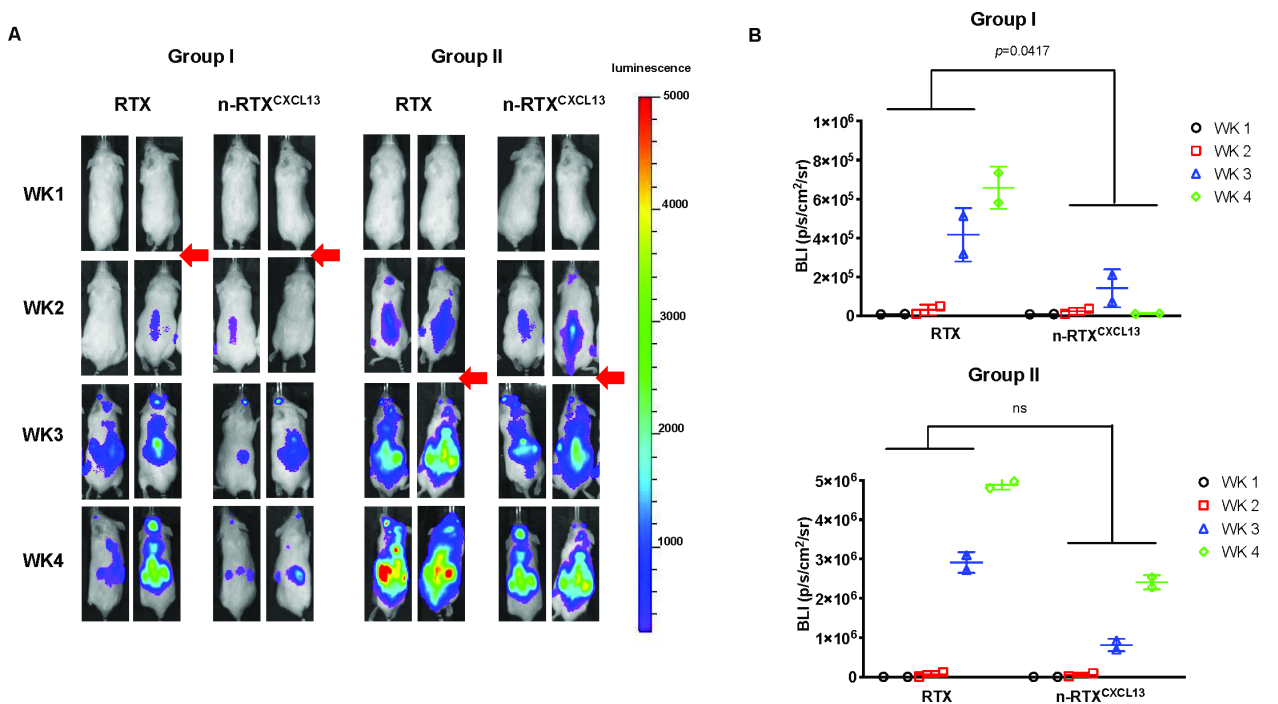

Figure 3 Improved antilymphoma efficacy of $n-R^{-C X C L 13}$ in xenograft NSG ${ }^{-H c 1}$ mice. 2F7-BR44 cells were injected into NSG ${ }^{-}$ ${ }^{\mathrm{Hc}}$ mice via the tail vein $\left(2 \times 10^{6}\right.$ /animal) $(\mathrm{n}=2)$. Xenograft mice were treated with native RTX or $\mathrm{n}-\mathrm{RTX}{ }^{\mathrm{CXCL13}}$ at week 1 (group I) or week 2 (group II) after 2F7-BR44 cell injection. Native RTX and n-RTX ${ }^{\mathrm{CXCL} 13}$ were injected via the retro-orbital vein (4 mg/kg/day for 5 sequential days). (A) Lymphoma progression and metastasis were monitored weekly by bioluminescence imaging using an IVIS Lumina II In Vivo Imaging system. Sensitivity settings were adjusted at each time point to maintain 250-5000 counts per pixel and assigned the same color scale for all time points. (B) Bioluminescence intensity (BLI) values in the whole body were compared between group I and group II with RTX and n-RTXCXCL13 treatment. Data are shown means \pm SDs. Statistical significance was calculated with means at all four time points using a $p$ value. $P$ values were calculated by Wilcoxon matchedpaired test with Spearman's rank correlation. ns: not significant.

RTX when treatment was initiated at an early time point (1 week post xenograft); however, such effects were not observed when the treatment was started at a later time point ( 2 weeks post xenograft). ${ }^{9}$ In that system, the death of 2F7-BR44 cells was considered to be induced mainly by RTX-mediated direct killing (apoptosis ${ }^{22}$ due to the lack of a functional complement system required for the induction of CDC and immune cells supporting antibodydependent effector activities such as ADCC and ADCP. To confirm improved antilymphoma activity supporting CDC in $\mathrm{NSG}^{-\mathrm{Hcl}}$ mice, we repeated the experiments using both xenograft NSG and $\mathrm{NSG}^{-\mathrm{Hc} 1}$ mice side-by-side (compare figure 3 with online supplemental figure S4). Mice were treated with either native RTX or n-RTX ${ }^{\text {CXCL13 }}$ at both 1 week (group I) and 2 weeks post xenograft (group II). Lower lymphoma burden and slower progression were observed in $\mathrm{NSG}^{-\mathrm{Hcl}}$ mice treated with both RTX and n-RTX ${ }^{\text {CXCL13 }}$ (compare figure 1A with figure $3 \mathrm{~A}$ ) relative to that in NSG mice (compare online supplemental figure S1 with online supplemental figure S4). Although the treatment at week 2 resulted in insufficient control of lymphoma proliferation in xenograft $\mathrm{NSG}^{-\mathrm{Hcl}}$ mice, n-RTX ${ }^{\text {CXCL13 }}$ still outperformed RTX in lymphoma control in group II (figure $3 \mathrm{~B}$ ). The therapeutic improvement elicited by n-RTX ${ }^{\mathrm{CXCL} 13}$ was significant with early treatment in group I; significance decreased with delayed treatment in group II $\mathrm{NSG}^{-\mathrm{Hcl}}$ mouse models. These results further confirmed that the n-RTX ${ }^{\text {CXCL3 }}$ mediated greater antilymphoma efficacy in 2F7-BR44 xenograft mice relative to that of native RTX and indicate that the antilymphoma efficacy of n-RTX ${ }^{\text {CXCL3 }}$ can be further heightened in the presence of functional complement. The improved therapeutic efficacy of n-RTX ${ }^{\text {CXCL13 }}$ in $\mathrm{NSG}^{-\mathrm{Hcl}}$ mice was further confirmed by two repeated sets (online supplemental figure S5).

\section{Functional complement system further enhances the} antilymphoma efficacy of RTX in humanized xenografted mice The humanization of NSG mice enables support of antibody-mediated effector activities such as ADCC and ADCP. $^{23}{ }^{24}$ We next evaluated the antilymphoma efficacy of RTX using a BLT (bone marrow/liver/thymus) humanized mouse model, which was used in our previous work. ${ }^{9}$ In BLT mice, human T, B, NK cells, and macrophages were confirmed to be in circulation (online supplemental figure S6). Notably, both NK cells and macrophages are known to mediate ADCC and ADCP. ${ }^{25}$ Compared with the limited efficacy exhibited by native RTX in the CNS due to the poor antibody penetration, we have demonstrated clearance of CNS lymphomas by n-RTX ${ }^{\text {CXCL13 }}$ treated at 1 week post xenograft in NSG-BLT mice. ${ }^{9}$ However, when treatment started at the later time point (2 weeks post xenograft), neither native RTX nor n-RTX ${ }^{\text {CXCL13 }}$ could suppress lymphoma proliferation in NSG-BLT mice, resulting in whole-body metastasis and animal death (figure 4A,D). The average survival time of the native RTX-treated group was 4 weeks post xenograft, while the n-RTX ${ }^{\mathrm{CXCL13}}$ treated group survival time was approximately 7 weeks post xenograft. In contrast, $\mathrm{NSG}^{-}$ ${ }^{\mathrm{Hcl}}$-BLT mice showed enhanced antilymphoma activity by treatment with both native RTX and n-RTX ${ }^{\text {CXCL13 }}$ even when treatment was initiated at 2 weeks post xenograft 


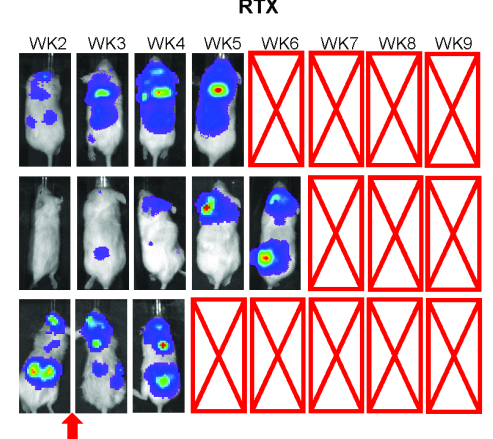

B

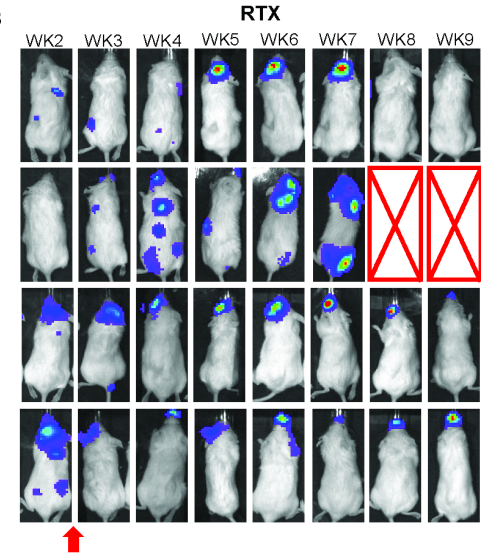

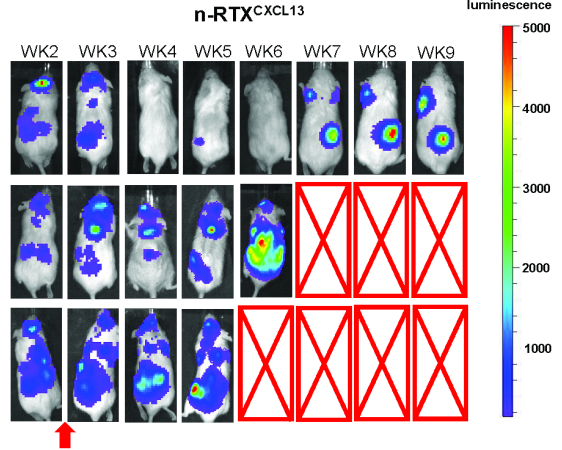

n-RTXCXCL13

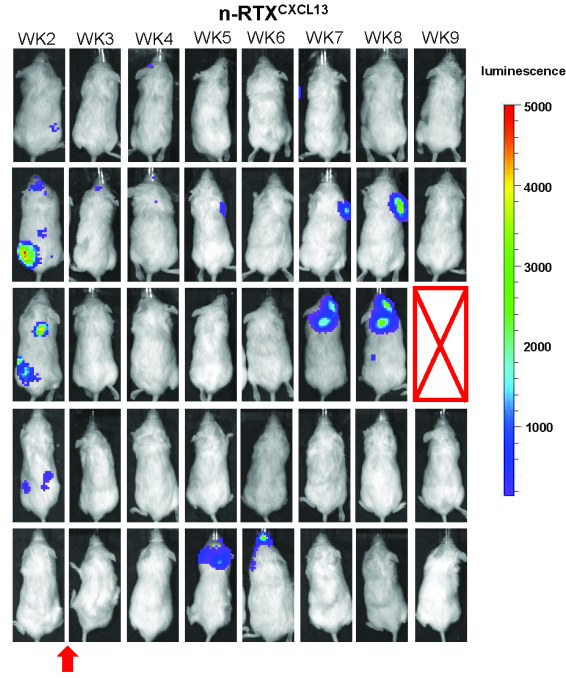

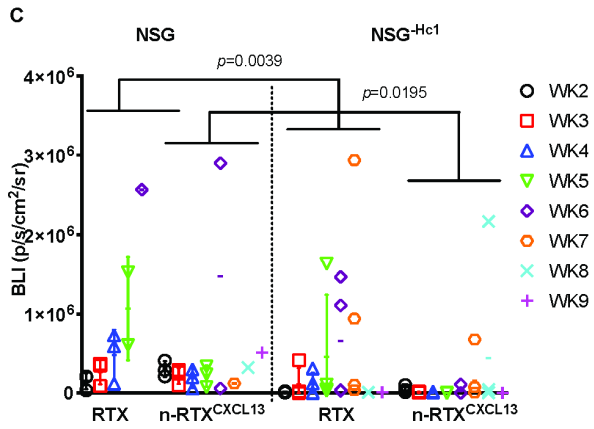

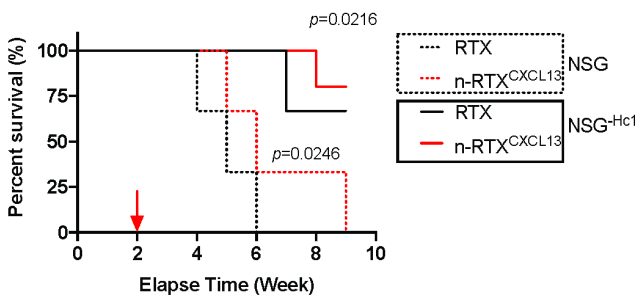

Figure 4 Antilymphoma efficacy of delayed treatment in humanized xenografted mice. Humanized NSG $(n=6)$ or NSG ${ }^{-H c 1}$ $(n=9)$ bioluminescence intensity (BLT mice were administered 2F7-BR44 cells via the tail vein $\left(2 \times 10^{6} /\right.$ animal). Xenograft mice were then treated with RTX or $\mathrm{n}-\mathrm{RTX}{ }^{\mathrm{CXCL13}}$ via retro-orbital vein injection $(4 \mathrm{mg} / \mathrm{kg} /$ day for five sequential days) at 2 weeks post xenograft (red arrows). Lymphoma progression in NSG-BLT mice (A) and NSG ${ }^{-H c 1}$-BLT mice (B) were monitored weekly by bioluminescence imaging using an IVIS Lumina II In Vivo Imaging system. Sensitivity settings were adjusted at each time point to maintain 150-5000 counts per pixel and assigned the same color scale for all timepoints. Boxes containing a red $X$ represent deceased mice. (C) BLI values in the whole body were compared between two kinds of humanized mice with RTX and $\mathrm{n}-\mathrm{RTX} \mathrm{XXCL13}^{\mathrm{C}}$ treatment. Data are shown means \pm SDs. Statistical significance was calculated with means at all time points using a $p$ value. $P$ values were calculated by Wilcoxon matched-paired signed rank test. (D) Kaplan-Meier survival curves of the NSG$\mathrm{BLT}$ and $\mathrm{NSG}^{-\mathrm{HC1}}$-BLT xenograft mice treated with RTX and $\mathrm{n}-\mathrm{RTX} \mathrm{CXCL13}^{\mathrm{C}}$ were plotted relative to the number of weeks after 2F7BR44 cell xenograft. Statistical significance was calculated with $p$ value by log-rank test.

(figure $4 \mathrm{~B})$. Herceptin $\left(\mathrm{n}-\mathrm{HER}^{\mathrm{CXCL} 13}\right)$, used as an irrelevant control antibody, did not show any therapeutic effect in either NSG-BLT or $\mathrm{NSG}^{-\mathrm{Hcl}}$-BLT mice (online supplemental figure S7). Although the BBB penetration of native RTX proved inefficient in NSG-BLT mice, three out of four $\mathrm{NSG}^{-\mathrm{Hcl}}$-BLT mice that received native RTX treatment were able to eliminate most tumors and showed no sign of relapse for at least 9 weeks post xenograft.
Conversely, n-RTX ${ }^{\text {CXCL13 }}$ mediated far superior antilymphoma efficacy, even against CNS lymphomas; all mice were able to completely eliminate tumors by week 6 , and four out of five mice were able to control lymphomagenesis with no relapse observed by week 9 . The enhanced lymphoma control in $\mathrm{NSG}^{-\mathrm{Hcl}}$-BLT mice compared with that in NSG-BLT mice was quantitatively confirmed through comparison of total BLIs (figure 4C) and survival 
rates (figure 4D). Moreover, the antilymphoma efficacy of RTX was further enhanced by the use of n-RTX CXCL13, allowing for enrichment of RTX around lymphomaseven those distributed within the CNS. ${ }^{9}$ These results indicate that $\mathrm{CDC}$ mediated by a functional complement system together with ADCC and ADCP could be the mechanism behind enhanced antilymphoma efficacy of RTX observed in the $\mathrm{NSG}^{-\mathrm{Hcl}}$-BLT mouse.

\section{Cell-associated antilymphoma response contributes to the control of lymphoma relapse in humanized $\mathrm{NSG}^{-\mathrm{Hc1}}$ xenografted mice}

Although levels of free RTX can only be maintained at a detectable concentration in plasma for 4 weeks in either native or nanoencapsulated forms (online supplemental figure S8), lymphomagenesis was well-controlled in most $\mathrm{NSG}^{-\mathrm{Hcl}}$-BLT mice over 9 weeks (figure 5). To understand the contribution of other potential mechanisms for controlling lymphoma, we performed a second transplant with the same number of 2F7-BR44 cells at 10 weeks post xenograft in surviving $\mathrm{NSG}^{-\mathrm{Hcl}}$-BLT mice as in figure 4B. The experimental scheme was summarized in online supplemental figure S9. Lymphoma growth was followed weekly by in vivo bioluminescence imaging for an additional 6 weeks (ie, from 10 weeks to 15 weeks post xenograft). Mice that previously received n-RTX ${ }^{\text {CXCL13 }}$ treatment did not allow additional lymphoma formation following the second xenotransplant (figure 5A, n-RTX-

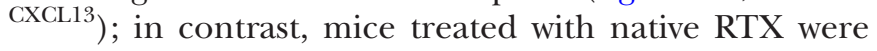
susceptible to the second xenotransplant (figure 5A, RTX). The levels of human B-cells in peripheral blood started to recover approximately 3 weeks post RTX administration (ie, at 5 weeks post-1st xenograft) and maintained at 4\%-9\% after 9 weeks post-1st xenograft (figure 5B). Contrastingly, levels of circulating 2F7-BR44 cells increased after the second xenograft in mice treated with native RTX but not with n-RTX ${ }^{\text {CXCL13 }}$, indicating that the failure of lymphoma growth after the second xenograft in mice treated with $\mathrm{n}-\mathrm{RTX}^{\mathrm{CXCL13}}$ was not due to residual RTX. Importantly, all mice treated with n-RTXCXCL13 achieved sustained control until the endpoint (16 weeks post-1st xenograft) with significant extension of survival time (figure 5C).

To confirm the potential mechanism responsible for preventing xenograft after the second transplant in n-RTX ${ }^{\text {CXCL13 }}$-treated mice, we eliminated $\mathrm{CD} 7^{+}$cells using a CD7-specific immunotoxin that uses saporin toxin as a mediator of cell death. ${ }^{26} \mathrm{CD} 7$ expression is present on most T cells, ${ }^{27}{ }^{28} \mathrm{NK}$ cells, and early stages of B and myeloid cells. ${ }^{29}$ As reported previously, nanocapsules can achieve broad systemic delivery of macromolecule cargos to sites including the lymph nodes, CNS, gut, thymus, spleen, liver, and kidneys of mice, rats and non-human primates. ${ }^{918}$ To ensure efficient elimination of $\mathrm{CD}^{+}$cells in animals, we encapsulated saporin within nanocapsules and conjugated anti-CD7 antibody on the surface $\left(\mathrm{n}\right.$-Saporin ${ }^{\text {anti-CD7 }}$ ) to target $\mathrm{CD} 7^{+}$cells in animals. Saporin mediates cell death by inhibiting protein synthesis through inactivation of the $60 \mathrm{~S}$ subunit of ribosomes after uptake by cells. ${ }^{30}$ However, internalization of saporin is inefficient, ${ }^{31}$ and our nanocapsule platform designed for RTX delivery using zwitterionic monomer MPC is unable to achieve efficient intracellular delivery. ${ }^{9} 17$ To achieve effective intracellular delivery of saporin, we nanoencapsulated saporin using a mixture of neutrally charged monomer acrylamide and positively charged monomer $\mathrm{N}$-(3-aminopropyl)methacrylamide. As a crosslinker, we used GDMA, which releases encapsulated saporin in low $\mathrm{pH}$ conditions, that is, in endosomes. With these modifications, $\mathrm{n}$-Saporin ${ }^{\text {anti-CD7 }}$ can be specifically internalized in cells expressing $\mathrm{CD} 7$ molecules through endocytosis, release saporin in endosomes due to low $\mathrm{pH}$ conditions, and thereafter mediate cell death. The specificity and efficiency of cell death induced by n-Saporin ${ }^{\text {anti-CD7 }}$ were assessed in human peripheral blood mononuclear cells ex vivo (online supplemental figure S10). The most dramatic reduction in cell number was seen in $\mathrm{CD} 56^{+}$/ CD3 $^{-}$NK cells (approximately 60\%), while amounts of both $\mathrm{CD}^{+} \mathrm{T}$ cells and total $\mathrm{CD} 8^{+} \mathrm{T}$ cells $\left(\mathrm{CD} 8^{\text {high }}\right.$ and $\mathrm{CD} 8^{\mathrm{dim}}$ ) derived from $\mathrm{CD}^{+} \mathrm{T}$ cells decreased by approximately $30 \%$. CD $19^{+} \mathrm{B}$ cells in the $\mathrm{CD} 45^{+}$population and $\mathrm{CD} 14^{+}$in the $\mathrm{CD}^{-} / \mathrm{CD}^{-} 9^{-}$population did not seem to be a major target of $\mathrm{n}$-Saporin ${ }^{\text {anti-CD7 }}$. NSG ${ }^{\mathrm{Hcl}}-\mathrm{BLT}$ mice that were successfully protected from the second xenograft were treated with either n-Saporin ${ }^{\text {anti-CD7 }}$ or unliganded n-Saporin as a control and monitored for 2F7-BR44 derived bioluminescence 1 week after $n$-Saporin ${ }^{\text {anti-CD7 }}$ administration (figure 5D). Mice treated with n-Saporin ${ }^{\text {an- }}$ ti-CD7, but not control n-Saporin, lost their antilymphoma control. These results strongly suggested that $\mathrm{CD} 7^{+}$cells, mainly NK cells and T cells to some capacity, in these mice play an important role in cell-associated antilymphoma response in n-RTX ${ }^{\mathrm{CXCL} 13}$-treated $\mathrm{NSG}^{-\mathrm{Hcl}}$-BLT mice.

\section{DISCUSSION}

Here, we show that a novel NSG strain of BLT mice possessing the corrected $H c$ gene, $\mathrm{NSG}^{-\mathrm{HCl}}$, supports greater antilymphoma activity mediated by RTX than NSG BLT mice used in previous research. ${ }^{9}$ In addition to their possession of an immune system that mediates ADCC and ADCP, $\mathrm{NSG}^{-\mathrm{HCl}}$ BLT mice have a fully functional complement system capable of supporting CDC that is not present in NSG BLT mice due to a 2 bp deletion in the $H c$ gene. ${ }^{14}$ Previously, we have shown that nanocapsulation and CXCL13 ligand targeting of RTX allows for deeper penetration into tissues compared with native RTX; thus, we expect that the antilymphoma activity of n-RTX ${ }^{\text {CXCL13 }}$ may occur at the local lymphoma level through ADCC, ADCP, or CDC. ${ }^{9}$ This may also result in the priming of immune cells within lymph nodes, leading to an increase in systemic antilymphoma effector cells. RTX is known to direct anti-lymphoma ADCC and CDC activities, ${ }^{32}$ which would only be both effective in $\mathrm{NSG}^{-\mathrm{HCl}}$ BLT mice. These complement-dependent activities and 


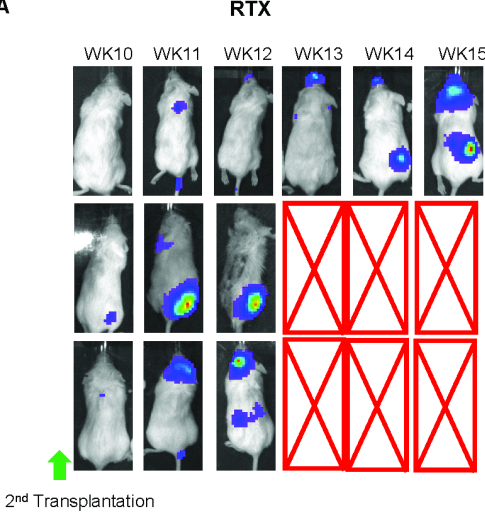

n-RTXCXCL13

Figure 5 Cell associated antilymphoma response contributes to lymphoma suppression in $\mathrm{NSG}^{-\mathrm{Hc}^{1}}$-bioluminescence intensity (BLT) xenografted mice treated with $n-R T X^{C X C L 13}$. 2F7-BR44 xenograft NSG ${ }^{-H c 1}$-BLT mice treated with RTX $(n=3)$ and $n-$ $\operatorname{RTX}^{\operatorname{CXCL13}}(n=4)$ as shown in figure 4 received a second xenograft of 2F7-BR44 cells via the tail vein $\left(2 \times 10^{6} /\right.$ animal $)$ at week 10 post-1st xenograft. (A) Lymphoma progression was monitored weekly after second xenograft by bioluminescence imaging using an IVIS Lumina II In Vivo Imaging system. Sensitivity settings were adjusted at each time point to maintain 150-5000 counts per pixel and assigned the same color scale for all time points. Boxes containing a red $\mathrm{X}$ represent deceased mice. Peripheral blood was collected from mice at weeks $0,3,5,7,9,11,12,13$, and 16 post 1st xenograft. (B) Blood samples were processed and stained with antibodies to monitor changes in peripheral B cells and 2F7-BR44 cells over the course of experiment. 2F7-BR44 cells were monitored by genetic labeling of mStrawberry expression. (C) Kaplan-Meier survival curves of xenograft NSG ${ }^{-\mathrm{Hc}^{1}}$-BLT mice treated with RTX and n-RTX ${ }^{C X C L 13}$ were plotted relative to the number of weeks post-1st xenograft. Statistical significance was calculated with $p$ value by log-rank test. (D) Four $n-R T X^{\mathrm{CXCL13}}$ treated $\mathrm{NSG}^{-\mathrm{HC1}}-\mathrm{BLT}$ mice were randomly separated into two groups. One group $(n=2)$ was treated with encapsulated immunotoxin $n-S a p o r i n^{\text {anti-CD7 }}$ at week 20 post-1 st xenograft, while the other group $(n=2)$ was treated with PBS and used as a control. Lymphoma relapse was monitored before $n-S a p o r i n{ }^{\text {anti-CD7 }}$ treatment at week 20 and 1 week after $n$-Saporin ${ }^{\text {anti-CD7 }}$ treatment at week 21 by bioluminescence imaging using an IVIS Lumina II In Vivo Imaging system. Sensitivity settings were adjusted at each time point to maintain 150-5000 counts per pixel and assigned the same color scale for all time points.

cellular antilymphoma response demonstrate the superiority of $\mathrm{NSG}^{-\mathrm{HCl}}$ BLT in conducting anticancer antibody efficacy in vivo.

The antitumor cellular response involves members of the innate and adaptive immune systems. ${ }^{33}$ Antigen-presenting cells, especially dendritic cells, are key in the initiation of antitumor adaptive immune response by collecting antitumor antigens. These cells trigger NK cell-dendritic cell crosstalk, which activates both cells to stimulate antitumor activity mediated by NK cells as well as tumor-specific T cell 
expansion stimulated by dendritic cells, ${ }^{34}$ the production of effector-type $\mathrm{T}$ cells, and plasma cells which in turn produce antitumor antibodies. ${ }^{35}$ Effector $\mathrm{CD} 8^{+} \mathrm{T}$ cells directly lyse tumor cells though the use of elements such as granzyme $\mathrm{B}$ and perforin on recognition of major histocompatibility complex (MHC) class I-presented antigens ${ }^{36}$ while $\mathrm{CD} 4^{+} \mathrm{T}$ helper cells provide support via cytokine production such as IL-2, TNF- $\alpha$, and IFN- $\gamma^{37}{ }^{38}$ These cytokines also support the activity of local antitumor macrophages and NK cells. ${ }^{39}$ In addition, NK cells in lymph nodes and tonsils have a helper role in the production of IFN-Y in response to IL-12, 15, 18, and type 1 IFN stimulation. ${ }^{40}$ The complement system acts in both a protumorigenic and antitumorigenic manner by effecting the recruitment of NK cells, $\mathrm{CD} 4^{+}$and $\mathrm{CD} 8^{+} \mathrm{T}$ cells, as well as promoting macrophage activation by production of IFN- $\gamma$; it can also promote the recruitment of myeloidderived suppressor cells and turn down antitumor $\mathrm{T}$ cell functions, all dependent on the local tumor microenvironment and concentrations of anaphylatoxins (C3a, C4a, and C5a). ${ }^{41}$ Therefore, it is important to evaluate the efficacy of antitumor therapeutics with an active complement system in the human immune microenvironment. We found that a functional complement system plays a key role in the induction of antitumor cellular response in 27F-BR44 xenograft $\mathrm{NSG}^{-\mathrm{HCl}}$ humanized mice treated with $\mathrm{n}-\mathrm{RTX}^{\mathrm{CXCL13}}$, which efficiently penetrates in most lymphoid tissues where extranodal lymphomas arise such as lymph nodes, spleen, gut, kidney, bone marrow, and brain. ${ }^{918}$ This effect was not seen in mice treated with native RTX, suggesting that the penetration of RTX deep into tissues via nanoencapsulation with MPC is of key importance for the induction of the antitumor cellular responses in the presence of a functional complement system.

It is also important to note that in our model system, we demonstrated enhanced efficacy of n-RTX ${ }^{\mathrm{CXCL} 13}$ compared with native RTX in the 2F7-BR44 xenograft mouse model. n-RTX ${ }^{\text {CXCL13 }}$ not only eliminated most detectable cancer metastases in our model but also prevented lymphoma growth in a lymphoma relapse model via the second xenograft (figure 5). This relapse prevention was disrupted by the elimination of $\mathrm{CD}^{+}$cells, especially NK cells and a subtype of $\mathrm{T}$ cells, indicating the cellular immune response was key in preventing cancer relapse as reported elsewhere. ${ }^{42}$ The use of native RTX alone has limited efficacy in humans and is often given in combination with cyclophosphamide, doxorubicin, vincristine, and prednisone (known as R-CHOP) for intractable lymphomas. ${ }^{43}$ However, vincristine and prednisone inhibit cellular-based antitumor activities through the dampening of dendritic cell, NK cell, and T cell responses. ${ }^{445}$ Our models predict that actions of the above cells are crucial in mediating antilymphoma cellular activity of n-RTX ${ }^{\text {CXCL13 }}$. With the greater efficacy of n-RTX ${ }^{\mathrm{CXCL} 13}$ compared with native RTX, the use of drugs such as vincristine and prednisone may not be necessary. Conversely, doxorubicin and cyclophosphamide actually potentiate the response through sensitization of tumor cells to $\mathrm{CD}^{+}$effector cell function. ${ }^{46}{ }^{47}$ Therefore, the use of n-RTX ${ }^{\text {CXCL13 }}$ in combinational treatments with these two drugs may greatly enhance antitumor cellular-mediated immunity compared with current regimens. ${ }^{48}$ Moreover, PD-1/PD-L1 checkpoint blockades maintain the activity of complement Clq polarized macrophages and proliferation of inflammatory T cells ${ }^{49}$; the combination of PD-1/PD-L1 checkpoint blockades and RTX has shown promise as a clinically efficient strategy for relapsed lymphomas. The blockade of C5a also demonstrated the ability to work synergistically with anti-PD-1 inhibition by activation of $\mathrm{CD}^{+} \mathrm{T}$ cells and inhibition of myeloid-derived suppressor cells. ${ }^{50}$ Since active complement is essential in these combinational treatments, the use of an $\mathrm{NSG}^{-\mathrm{HCl}}$ BLT xenograft mouse model has proven itself as a powerful mouse model for evaluation of immunotherapeutic antitumor efficacy in a near-complete human immune environment.

\section{Author affiliations}

${ }^{1}$ Department of Microbiology, Immunology and Molecular Genetics, David Geffen School of Medicine, University of California Los Angeles, Los Angeles, California, USA

${ }^{2}$ UCLA AIDS Institute, University of California Los Angeles, Los Angeles, California, USA

${ }^{3}$ Department of Chemical and Biomolecular Engineering, University of California Los Angeles, Los Angeles, California, USA

${ }^{4}$ Microbiology, University of Alabama at Birmingham School of Arts and Humanities, Birmingham, Alabama, USA

Correction notice This article has been corrected since it first published. The provenance and peer review statement has been included.

Acknowledgements The authors thank Dr Jeffrey Brand for editing the manuscript.

Contributors JW and LW contributed equally. JW, LW, and MK proposed the concept, designed this study, developed the methodology, and analyzed and interpreted data (eg, statistical analysis, biostatistics, computational analysis). JW, LW, JR, EK, SC, DW, TK, and MK performed acquisition of data (provided animals, acquired and managed patients, provided facilities, etc). ISY. Chen and YL provided administrative, technical, or material support (ie, reporting or organizing data, constructing databases). MK supervised the whole study.

Funding This work was supported by NIH grants CA232015 and Al110200 (MK), and CA253215 (JW). Equipment located in the UCLA AIDS Institute is supported by the James B Pendleton Charitable Trust.

Competing interests None declared.

Patient consent for publication Not required.

Provenance and peer review Not commissioned; externally peer reviewed.

Data availability statement The authors declare that all data supporting the results in this study are available within the paper and its supplementary information. Source data for the figures in this study are available from the corresponding author upon reasonable request.

Supplemental material This content has been supplied by the author(s). It has not been vetted by BMJ Publishing Group Limited (BMJ) and may not have been peer-reviewed. Any opinions or recommendations discussed are solely those of the author(s) and are not endorsed by BMJ. BMJ disclaims all liability and responsibility arising from any reliance placed on the content. Where the content includes any translated material, BMJ does not warrant the accuracy and reliability of the translations (including but not limited to local regulations, clinical guidelines, terminology, drug names and drug dosages), and is not responsible for any error and/or omissions arising from translation and adaptation or otherwise.

Open access This is an open access article distributed in accordance with the Creative Commons Attribution Non Commercial (CC BY-NC 4.0) license, which permits others to distribute, remix, adapt, build upon this work non-commercially, and license their derivative works on different terms, provided the original work is properly cited, appropriate credit is given, any changes made indicated, and the use is non-commercial. See http://creativecommons.org/licenses/by-nc/4.0/. 
ORCID iD

Masakazu Kamata http://orcid.org/0000-0003-0323-3742

\section{REFERENCES}

1 Buss NAPS, Henderson SJ, McFarlane M, et al. Monoclonal antibody therapeutics: history and future. Curr Opin Pharmacol 2012;12:615-22.

2 Zhou J, Bashey A, Zhong R, et al. CTLA-4 blockade following relapse of malignancy after allogeneic stem cell transplantation is associated with $\mathrm{T}$ cell activation but not with increased levels of $\mathrm{T}$ regulatory cells. Biol Blood Marrow Transplant 2011;17:682-92.

3 Zhang Y, Zhang G-L, Sun X, et al. Establishment of a murine breast tumor model by subcutaneous or orthotopic implantation. Oncol Lett 2018;15:6233-40.

4 Zhao Y, Shuen TWH, Toh TB, et al. Development of a new patientderived xenograft humanised mouse model to study humanspecific tumour microenvironment and immunotherapy. Gut 2018;67:1845-54

5 van Marion DMS, Domanska UM, Timmer-Bosscha $\mathrm{H}$, et al. Studying cancer metastasis: existing models, challenges and future perspectives. Crit Rev Oncol Hematol 2016;97:107-17.

6 Stern M, Herrmann R. Overview of monoclonal antibodies in cancer therapy: present and promise. Crit Rev Oncol Hematol 2005;54:11-29.

7 Skelton JK, Ortega-Prieto AM, Dorner M. A hitchhiker's guide to humanized mice: new pathways to studying viral infections. Immunology 2018;154:50-61.

8 Brainard DM, Seung E, Frahm N, et al. Induction of robust cellular and humoral virus-specific adaptive immune responses in human immunodeficiency virus-infected humanized BLT mice. J Virol 2009;83:7305-21.

9 Wen J, Wu D, Qin M, et al. Sustained delivery and molecular targeting of a therapeutic monoclonal antibody to metastases in the central nervous system of mice. Nat Biomed Eng 2019;3:706-16.

10 Baxter AG, Cooke A. Complement lytic activity has no role in the pathogenesis of autoimmune diabetes in NOD mice. Diabetes 1993;42:1574-8.

11 Puchalapalli M, Zeng X, Mu L, et al. NSG mice provide a better spontaneous model of breast cancer metastasis than athymic (Nude) mice. PLoS One 2016;11:e0163521.

12 Ratelade J, Verkman AS. Inhibitor(s) of the classical complement pathway in mouse serum limit the utility of mice as experimental models of neuromyelitis optica. Mol Immunol 2014;62:104-13.

13 Reis ES, Mastellos DC, Ricklin D, et al. Complement in cancer: untangling an intricate relationship. Nat Rev Immunol 2018;18:5-18.

14 Verma MK, Clemens J, Burzenski L, et al. A novel hemolytic complement-sufficient NSG mouse model supports studies of complement-mediated antitumor activity in vivo. J Immunol Methods 2017;446:47-53.

15 Rafiq K, Bergtold A, Clynes R. Immune complex-mediated antigen presentation induces tumor immunity. J Clin Invest 2002;110:71-9.

16 Schuurhuis $\mathrm{DH}$, van Montfoort N, loan-Facsinay A, et al. Immune complex-loaded dendritic cells are superior to soluble immune complexes as antitumor vaccine. J Immunol 2006;176:4573-80.

17 Wu D, Qin M, Xu D, et al. A Bioinspired platform for effective delivery of protein therapeutics to the central nervous system. Adv Mater 2019;31:e1807557:1807557.

18 Qin M, Wang L, Wu D, et al. Enhanced delivery of rituximab into brain and lymph nodes using Timed-Release nanocapsules in non-human primates. Front Immunol 2019;10:3132.

$19 \mathrm{Ng} \mathrm{VL}$, Hurt MH, Fein CL, et al. IgMs produced by two acquired immune deficiency syndrome lymphoma cell lines: Ig binding specificity and $\mathrm{VH}$-gene putative somatic mutation analysis. Blood 1994;83:1067-78.

20 Vogel C-W, Fritzinger DC. Cobra venom factor: structure, function, and humanization for therapeutic complement depletion. Toxicon 2010;56:1198-222

21 Haihua C, Wei W, Kun H, et al. Cobra venom factor-induced complement depletion protects against lung ischemia reperfusion injury through alleviating blood-air barrier damage. Sci Rep 2018;8:10346.

22 Pedersen IM, Buhl AM, Klausen P, et al. The chimeric anti-CD20 antibody rituximab induces apoptosis in B-cell chronic lymphocytic leukemia cells through a p38 mitogen activated protein-kinasedependent mechanism. Blood 2002;99:1314-9.

23 Ito R, Maruoka S, Gon Y, et al. Recent advances in allergy research using humanized mice. Int J Mol Sci 2019;20. doi:10.3390/ ijms20112740. [Epub ahead of print: 04 Jun 2019].
24 Ito $\mathrm{A}$, Ishida $\mathrm{T}$, Yano $\mathrm{H}$, et al. Defucosylated anti-CCR4 monoclonal antibody exercises potent ADCC-mediated antitumor effect in the novel tumor-bearing humanized NOD/Shi-scid, IL-2Rgamma(null) mouse model. Cancer Immunol Immunother 2009;58:1195-206.

25 Campbell KS, Cohen AD, Pazina T. Mechanisms of NK cell activation and clinical activity of the therapeutic SLAMF7 antibody, Elotuzumab in multiple myeloma. Front Immunol 2018;9:2551.

26 Morland BJ, Barley J, Boehm D, et al. Effectiveness of HB2 (antiCD7)-saporin immunotoxin in an in vivo model of human T-cell leukaemia developed in severe combined immunodeficient mice. $\mathrm{Br}$ $J$ Cancer 1994;69:279-85.

27 Bárcena A, Muench MO, Roncarolo MG, et al. Tracing the expression of CD7 and other antigens during T- and myeloid-cell differentiation in the human fetal liver and thymus. Leuk Lymphoma 1995;17:1-11.

28 Aandahl EM, Sandberg JK, Beckerman KP, et al. CD7 is a differentiation marker that identifies multiple CD8 T cell effector subsets. J Immunol 2003;170:2349-55.

29 Sempowski GD, Lee DM, Kaufman RE, et al. Structure and function of the CD7 molecule. Crit Rev Immunol 1999;19:331-48.

30 Polito L, Bortolotti M, Mercatelli D, et al. Saporin-S6: a useful tool in cancer therapy. Toxins 2013;5:1698-722.

31 Weng A, Thakur M, von Mallinckrodt B, et al. Saponins modulate the intracellular trafficking of protein toxins. $J$ Control Release 2012;164:74-86.

32 Weiner GJ. Rituximab: mechanism of action. Semin Hematol 2010;47:115-23.

33 Gonzalez H, Hagerling C, Werb Z. Roles of the immune system in cancer: from tumor initiation to metastatic progression. Genes Dev 2018;32:1267-84.

34 Lee SC, Srivastava RM, López-Albaitero A, et al. Natural killer (NK): dendritic cell (DC) cross talk induced by therapeutic monoclonal antibody triggers tumor antigen-specific T cell immunity. Immunol Res 2011;50:248-54.

35 Tran Janco JM, Lamichhane P, Karyampudi L, et al. Tumor-Infiltrating dendritic cells in cancer pathogenesis. J Immunol 2015;194:2985-91.

36 Hanson HL, Donermeyer DL, Ikeda H, et al. Eradication of established tumors by CD8+ T cell adoptive immunotherapy. Immunity 2000;13:265-76.

37 Kalams SA, Walker BD. The critical need for CD4 help in maintaining effective cytotoxic T lymphocyte responses. J Exp Med 1998;188:2199-204.

38 Pardoll DM, Topalian SL. The role of CD4+ T cell responses in antitumor immunity. Curr Opin Immunol 1998;10:588-94.

39 Shankaran V, Ikeda H, Bruce AT, et al. Ifngamma and lymphocytes prevent primary tumour development and shape tumour immunogenicity. Nature 2001;410:1107-11.

40 Castro F, Cardoso AP, Gonçalves RM, et al. Interferon-Gamma at the crossroads of tumor immune surveillance or evasion. Front Immunol 2018;9:847

41 Roumenina LT, Daugan MV, Petitprez F, et al. Context-Dependent roles of complement in cancer. Nat Rev Cancer 2019;19:698-715.

42 Song C, Phuengkham H, Kim YS, et al. Syringeable immunotherapeutic nanogel reshapes tumor microenvironment and prevents tumor metastasis and recurrence. Nat Commun 2019;10:3745.

43 Siddhartha G, Vijay P. R-CHOP versus R-CVP in the treatment of follicular lymphoma: a meta-analysis and critical appraisal of current literature. J Hematol Oncol 2009;2:14.

44 Markasz L, Stuber G, Vanherberghen B, et al. Effect of frequently used chemotherapeutic drugs on the cytotoxic activity of human natural killer cells. Mol Cancer Ther 2007;6:644-54.

45 Rubio MT, Ittelet D, Raymond E, et al. The immunosuppressive effect of vincristine on allostimulatory potential of human dendritic cells interferes with their function and survival. Int $J$ Oncol 2004;25:407-12.

46 Casares N, Pequignot MO, Tesniere A, et al. Caspase-Dependent immunogenicity of doxorubicin-induced tumor cell death. J Exp Med 2005;202:1691-701.

47 van der Most RG, Currie AJ, Cleaver AL, et al. Cyclophosphamide chemotherapy sensitizes tumor cells to TRAIL-dependent CD8 T cellmediated immune attack resulting in suppression of tumor growth. PLoS One 2009;4:e6982.

48 Chen Y-L, Chang M-C, Cheng W-F. Metronomic chemotherapy and immunotherapy in cancer treatment. Cancer Lett 2017;400:282-92.

49 Clarke EV, Weist BM, Walsh CM, et al. Complement protein C1q bound to apoptotic cells suppresses human macrophage and dendritic cell-mediated Th17 and Th1 T cell subset proliferation. J Leukoc Biol 2015;97:147-60.

50 Ajona D, Ortiz-Espinosa S, Moreno H, et al. A combined PD-1/C5a blockade synergistically protects against lung cancer growth and metastasis. Cancer Discov 2017;7:694-703. 


\section{Correction: Nanoencapsulated rituximab mediates superior cellular immunity against metastatic B-cell lymphoma in a complement competent humanized mouse model}

Wen J, Wang L, Ren J, et al. Nanoencapsulated rituximab mediates superior cellular immunity against metastatic B-cell lymphoma in a complement competent humanized mouse model. J Immunother Cancer 2021;9:e001524. doi: 10.1136/jitc-2020-001524.

This article has been corrected since it first published. The provenance and peer review statement has been added.

Open access This is an open access article distributed in accordance with the Creative Commons Attribution Non Commercial (CC BY-NC 4.0) license, which permits others to distribute, remix, adapt, build upon this work non-commercially, and license their derivative works on different terms, provided the original work is properly cited, appropriate credit is given, any changes made indicated, and the use is non-commercial. See http://creativecommons.org/licenses/by-nc/4.0/.

C Author(s) (or their employer(s)) 2021. Re-use permitted under CC BY-NC. No commercial re-use. See rights and permissions. Published by BMJ.

J Immunother Cancer 2021;9:e001524corr1. doi:10.1136/jitc-2020-001524corr1

A) Check for updates 